\title{
The status of earthquake prediction
}

\section{MAX WYSS}

The contributions to the debate about earthquake prediction research in Nature so far, clearly show that we have hardly scratched the surface of the problem of how earthquake ruptures initiate and how to predict them. This arises from the difficulty of the problem and the lack of a vigorous program to study these questions. As Andrew Michael has said, funding for earthquake prediction research is a small fraction of the seismology program, in the U.S., and seismology is poorly funded compared to disciplines like astronomy.

\section{Great efforts over the past 100 years?!}

The contributions of Bernard, Michael and Scholz to this debate show that we have only a rudimentary understanding of the physics of earthquake ruptures, of transients in the Earth's crust and of the possibility of predicting earthquakes. They also point out that numerous crustal parameters may contain relevant information, but that no generally accepted, irrefutably hard evidence exists for any of these that would allow reliable earthquake prediction.

In this debate Geller repeats the exaggeration "Over the past 100 years, and particularly since 1960, great efforts, all unsuccessful, have been made to find such hypothetical precursors." Such strong wording was not acceptable in his recent article in the Geophysical Journal International, because articles in that journal are reviewed. The facts are that the first blue print on prediction research was not assembled until the mid 1960's and that blue print was not followed. No prediction research program existed before the 1970s and after the short flurry of activity in the mid 1970s, funding in the US and Europe dried up. Those of us who work in the field of earthquake rupture or prediction, know from first hand experience that when seeking research funding, the expression "earthquake prediction" in a research proposal to the NSF or the USGS will guarantee that it will not be funded.

There is no question in my mind that we will make no serious progress toward learning how to predict earthquakes, unless we assure high quality control in prediction research and start to fund it at a scale comparable to the funding of astrophysical research.

\section{The definition of earthquake prediction}

The definition of "earthquake prediction" as one leading to "a planned evacuation" by the moderator of this debate is not likely to be accepted, because social scientists warn that evacuations may do more harm than good, and because an accepted definition exists. A valid earthquake prediction is any statement that specifies

- Location $>$ uncertainty

- Size $>$ uncertainty

- Occurrence time uncertainty

- Probability of the prediction being fulfilled 2 .

Since there exist a number of different types of consumers (individuals, officials, government agencies, insurance and other companies, police and fire fighting departments), predictions with vastly different uncertainties are of interest. The consumer can judge from the uncertainties, whether or not a given prediction is useful. Insurance companies and those who make decisions on reinforcing old buildings are more interested in long term predictions with large uncertainties, than in accurate short term predictions. 


\section{The engineering solution is not enough}

Everyone, except perhaps some real estate developers, and builders of nuclear reactors and high dams, agree that we should build according to strict codes assuring earthquake resistance. However, the great majority of people will live and work for the next 50 years in buildings existing today and having been built when lax codes were in force. The sad fact is that in most parts of the world there is no money available to reinforce these buildings. Hence,

long- and intermediate-term predictions as a motivating force for precautions ${ }^{1}$, as well as short-term prediction, if attainable, are bound to benefit people significantly, if they are based on sound science and responsibly announced.

If the current knowledge of the earthquake initiation process is so poorly founded that experienced researchers can maintain the profound differences of opinion present in this debate, we are in desperate need of the major research effort that is not ${ }^{1}$ at present being made.

\section{Max Wyss}

Geophysical Institute, University of Alaska, Fairbanks, Alaska, USA.

\section{References}

1. Geller, R. J. Earthquake prediction: A critical review, Geophys. J. Int. 131, 425-450 (1997).

2. Allen, C. R. Responsibilities in earthquake prediction, Bull Seism. Soc. Amer. 66, 2069-2074, (1976). 